\title{
A New Practical Intracerebral Hematoma Volume Calculation Method and Comparison to simple ABC/2
}

\author{
Ferhat CUCE ${ }^{1}$, Gokalp TULUM², Ozgur DANDIN${ }^{3}$, Tuncer ERGIN¹ ${ }^{1}$ Omer KARADAS ${ }^{4}$, Onur OSMAN ${ }^{2}$ \\ ${ }^{1}$ Gulhane Education and Training Hospital, Department of Radiology, Ankara, Turkey \\ ${ }^{2}$ Istanbul Arel University, Department of Electrical and Electronics Engineering, Istanbul, Turkey \\ ${ }^{3}$ Gulhane Education and Training Hospital, Department of General Surgery, Ankara, Turkey \\ ${ }^{4}$ Gulhane Education and Training Hospital, Department of Neurology, Ankara, Turkey \\ This study has been presented as an oral presentation at the Balkan Radiology Congress between 12 and 14 October in 2017 at Budapest, Hungary.
}

Corresponding author: Omer KARADAS dromerkaradas@gmail.com

\section{ABSTRACT}

AIM: To find a more practical and effective formula than simple $\mathrm{ABC} / 2(\mathrm{~s} A \mathrm{BC} / 2)$ to calculate the hematoma volume in patients with subdural and parenchymal haemorrhage.

MATERIAL and METHODS: We reviewed the records of 157 patients who underwent brain computed tomography examinations for stroke from January to October 2017. Our method, sABC/2 formula, and the planimetric method (the gold standard) were used for measuring the volumes of hematoma.

RESULTS: The concordance in brain hematoma volumes calculated by $\mathrm{sABC} / 2$ and the proposed method as compared to planimetry were 0.92 and 0.93 , respectively $(p<0.05)$. The proposed method calculates the subdural hematoma volumes much better than the conventional one, and the root mean square error (RMSE) values were 32.17 and $20.62 \mathrm{ml}$ for sABC/2 and our new method, respectively, whereas the RMSE values for parenchymal hematomas were 25.01 and $20.46 \mathrm{ml}$ for sABC/2 and our new method, respectively.

CONCLUSION: Our new formula for calculating the volume of subdural and parenchymal hematomas is as practical as sABC/2 and allows the clinician to apply the method bedside.

KEYWORDS: Brain, Cerebral hemorrhage, Computed tomography, Volume, Calculation, ABC/2

\section{INTRODUCTION}

$\mathrm{T}$ The most devastating type of stroke is the intracerebral haemorrhage $(\mathrm{ICH})$, and $30 \%-50 \%$ of the patients with $\mathrm{ICH}$ die within 30 days of onset. The cerebral hematoma volume is an independent predictor of clinical outcomes and one of the scoring parameters used to predict monthly morbidity and mortality of a patient (8). Thus, the calculation of accurate hematoma volume at admission and its progression during hospitalisation is crucial for clinical prognosis.
In neuroradiology, the most common and practical formula to calculate hematoma volume is simple $A B C / 2(\mathrm{~s} A B C / 2)$ $(2,4,6,8,11,13,15,16,18)$. The planimetric method, which depends on a software, is the gold standard; however, in practice, it is not yet available. The present study is about the use of $\mathrm{sABC} / 2$, a practical formula for clinicians and radiologists in the computation of acute parenchymal hematoma $(\mathrm{PH})$, and subdural hematoma $(\mathrm{SH})$ volumes and the derivation of a more effective formula.
Ferhat CUCE (10:0000-0003-1831-3868

Gokalp TULUM : (1) : 0000-0003-1906-0401

Ozgur DANDIN : (D) :0000-0002-7386-6871
Tuncer ERGIN

Omer KARADAS

Onur OSMAN
(1) : 0000-0002-2407-8844

(1) : 0000-0003-0457-3722

(D) : 0000-0001-7675-7999 


\section{MATERIAL and METHODS}

This prospective study was approved by the hospital's institutional review board (no: 1491-987-10/1539). The data of consecutive patients with acute cerebral hematoma, presenting to the emergency department between January and October 2017, were collected. A written informed consent was waived by the local institutional review board.

\section{Study Population}

Brain computed tomography (CT) images of 157 patients, who were admitted to the emergency department with the diagnosis of acute haemorrhagic stroke, were enrolled in the study. All patients underwent a brain CT without contrast agent within 24 hours after the onset of symptoms. Diagnosis was made by two radiologists (F.C, T.E.) and confirmed by a neurologist (O.K).

A total of 79 patients with $<18$ years of age, brain tumour and metastasis, traumatic haemorrhage, arteriovenous malformation or image motion artefacts were excluded from the study. Finally, 78 patients with 90 hematomas were included in the study for further statistical analysis.

\section{CT Technique}

All examinations were performed on 64-slice CT scanner (Brilliance 64; Philips Healthcare, Cleveland, Ohio, USA) providing 4-cm coverage. Exposure parameters were 120 $\mathrm{kV}$ and $350 \mathrm{mAs}$. The collimation was $64 \times 0.625 \mathrm{~mm}$ and the images were obtained by axial acquisition. Matrix size was $512 \times 512$, and the field of view was $250 \mathrm{~mm}$. In addition, the images were reconstructed $3.0 \mathrm{~mm}$ thick on a transverse plane.

\section{Image Evaluation and Hematoma Volume Calculation Methods}

A total of 78 brain CT examination data sets were acquired in Digital Imaging and Communications in Medicine (DICOM) format. Appropriate image settings were performed for the CT, according to the hematoma type. PHs were evaluated using standard window widths (WW) and window levels (WL) to assess brain parenchyma (WW: 80, WL: 30). The SHs were evaluated with adjusted window settings to minimise the underestimation of hematoma thickness due to the proximity to the bone (WW: 250, WL: 100). The three lengths required for the $\mathrm{SABC} / 2$ formula were hand-traced by the radiologist. The two longest diameters [anteroposterior $(A)$ and transverse (B) diameters], perpendicular to each other, were calculated at the level of the widest dimension on the axial image. For the calculation of craniocaudal length $(\mathrm{C})$, the number of the slices between the start and end of the hematoma from the bottom to top, was calculated and multiplied by the slice thickness of $3 \mathrm{~mm}$. The units of all the lengths were in millimetres and those of the volume in millilitres. Finally, hematoma volume was calculated by the $\mathrm{SABC} / 2$ formula (Figure 1). The formulas, such as $\mathrm{C}$-weighted $\mathrm{ABC} / 2$ and $2 / 3$ sh in the literature, using the area of the hematoma, are not practical $(8,10,17)$. sABC/2 does not require area calculation and thus is considered as 'simple'.
The determination of hematoma shape and volume was performed. The shape of the $\mathrm{PH}$ was categorised into regular (round, ellipsoid and regular with convex margin) and irregular. $\mathrm{SH}$ s were not classified according to shape.

The hematoma volumes were calculated with $\mathrm{sABC} / 2$ and the proposed formula by a calculator as well as with the planimetric technique using the ManSeg 2.6 software. The planimetric analysis was performed using a semi-automated segmentation and volume calculation programme ManSeg 2.6 (1). Moreover, a joint decision of the observers was made in cases of disagreement, thus avoiding bias.

\section{The Two Step Method for Cerebral Hematoma Volume Calculation: TSM}

When the correlation coefficient $(r)$ between volume and three lengths (anteroposterior, transverse and craniocaudal diameters) of hematoma were investigated, it was observed that there was a significant relationship between volume

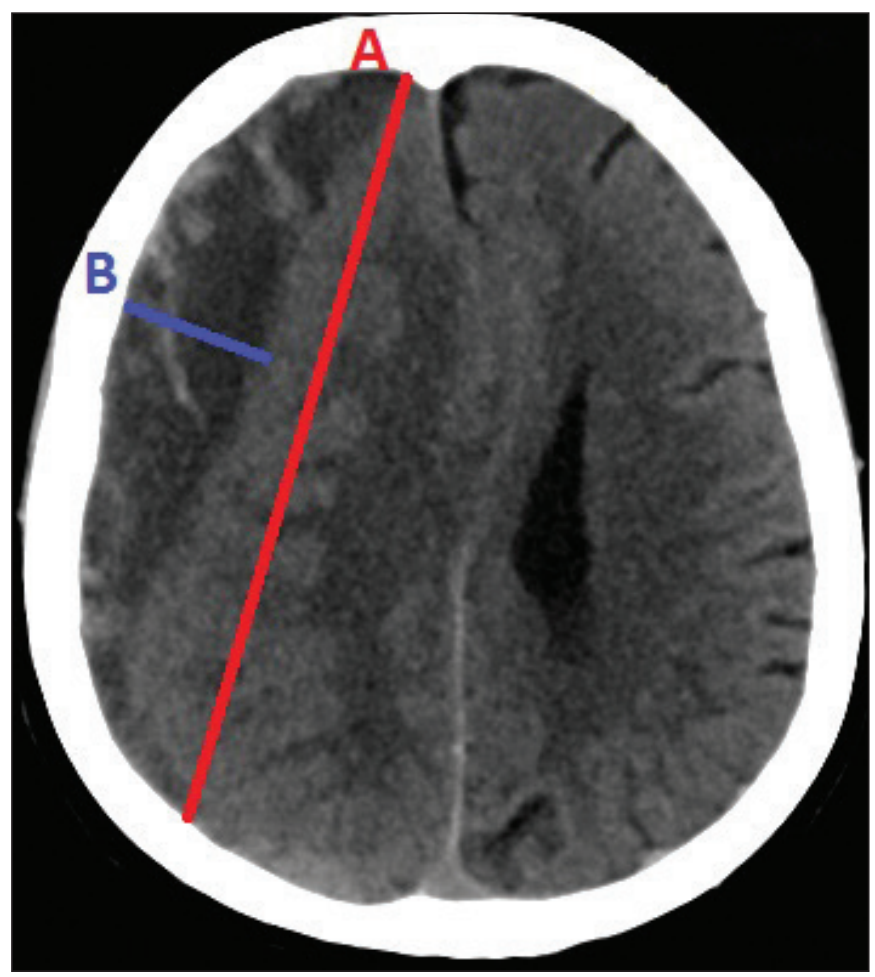

Figure 1: An acute onset chronic subdural hematoma case: The hematoma volume was calculated with both $A B C / 2$ and our proposed formula. The diameter of $C$ was $51 \mathrm{~mm}$ [as the number of the slice between the bottom and up (17 slice) was multiplied with the slice thickness of $3 \mathrm{~mm}$ ], the diameter of $A$ and $B$ was $101.4 \mathrm{~mm}$ and $19.4 \mathrm{~mm}$, respectively.

$\mathrm{sABC} / 2=101.4(\mathrm{~A}) \times 19.4(\mathrm{~B}) \times 51(\mathrm{C}) / 2=50.16 \mathrm{ml}$

Proposed formula: $0.3 A B C+30=0.3 \times 101.4(A) \times 19.4(B) \times 51$ (C) $+30=60.09 \mathrm{ml}$

[The result of the planimetric volume analysis (gold standart) of the case was $58.95 \mathrm{ml}$. While $\mathrm{sABC} / 2$ methods underestimated volume of hematoma with differences of $8.79 \mathrm{ml}$. The proposed method TSM has only $-1.14 \mathrm{ml}$ of the volume difference.] 
and anteroposterior diameter $(r=0.80$ for $p<0.05)$. Therefore we proposed two different linear functions to calculate the hematoma volume according to the anteroposterior diameter of the hematoma. In this work, the proposed linear functions and the related threshold diameters were determined in two steps.

While $30 \mathrm{ml}$ was taken into consideration as a grading score criteria for a hematoma volume, we firstly selected $45 \mathrm{ml}$ as a soft margin and applied least squares approximation to hematomas that are lower and higher than $45 \mathrm{ml}$ separately and determined two different linear functions. Second, we determined types of hematoma as regular parenchymal, irregular parenchymal, and crescent subdural hematoma. For each category, the anteroposterior diameter, which has the minimum error probability, determined as a threshold. In order to designate the relevant diameter for the threshold, we increased the threshold value $5 \mathrm{~mm}$ in each step and calculated the conditional probability. We obtained $50 \mathrm{~mm}$ diameter as the threshold for irregular and regular parenchymal hematomas (Volume of all irregular and regular parenchymal hematomas less than $50 \mathrm{~mm}$ in diameter were smaller than $45 \mathrm{ml}$. Also volume of all irregular and regular parenchymal hematomas greater than $50 \mathrm{~mm}$ in diameter were large than $45 \mathrm{ml}$ ) and $70 \mathrm{~mm}$ diameter as threshold for crescent subdural hematoma $(87.5 \%$ of crescent subdural hematoma had less than $70 \mathrm{~mm}$ in diameter were smaller than $45 \mathrm{ml}$. Also the volume of all crescent subdural hematoma greater than 70 $\mathrm{mm}$ in diameter were large than $45 \mathrm{ml}$.) Two linear equations for volume estimation of hematoma were given as,

If anteroposterior diameter $<50 \mathrm{~mm}$ for regular parenchymal hematoma

$V=0.45 A B C+1 \quad$ If anteroposterior diameter $<50 \mathrm{~mm}$ for irregular parenchymal hematoma

If anteroposterior diameter $<70 \mathrm{~mm}$ for crescent subdural hematoma

If anteroposterior diameter $>50 \mathrm{~mm}$ for regular parenchymal hematoma

$V=0.3 A B C+30$ If anteroposterior diameter $>50 \mathrm{~mm}$ for irregular parenchymal hematoma

If anteroposterior diameter $>70 \mathrm{~mm}$ for crescent subdural hematoma

\section{Statistical Analysis}

Agreement between planimetry and TSM was evaluated using Bland-Altman plots. Sensitivity, specificity, and AUC were calculated. Root mean square errors of the methods were obtained. Concordance between planimetry and volumes obtained by other estimation methods were assessed using $\mathrm{t}$ - test. Bland-Altman plots were generated for $\mathrm{sABC} / 2$ and TSM methods in comparison to the planimetric method using both original and log-transformed units.

\section{RESULTS}

Total 90 cerebral hematomas from 78 patients ( 29 females, 49 males) were evaluated for this study. The patients' mean age with standard deviation (SD) was $52.35 \pm 22.47$. The type and number of hematomas are given in Table $\mathrm{I}$.

The results of hematoma volumes calculated by both $\mathrm{sABC} / 2$ and our proposed formula:

While $\mathrm{SABC} / 2$ methods overestimated planimetry with mean differences of $-8.51 \mathrm{ml}$ the proposed method TSM has the only $-0.31 \mathrm{ml}$ of the mean difference.

Bland-Altman analysis illustrated that all methods were concordant with the planimetric method and no evidence of a linear trend (Figure 2, 3).

Variability in the concordance between planimetry and the two methods appeared to increase as volumes increased. Therefore, geometric Bland-Altman plots were drawn in the semi-log domain to evaluate concordance while compensating for issues of increasing variability (Figure 4, 5).

Table I: The Number of Hematoma Types and Volumes

\begin{tabular}{|c|c|c|}
\hline \multirow{2}{*}{$\begin{array}{l}\text { Hematoma Type and } \\
\text { Number (n) }\end{array}$} & \multicolumn{2}{|c|}{ Volume (ml) } \\
\hline & $<30 \mathrm{ml}$ & $>30 \mathrm{ml}$ \\
\hline Subdural $(\mathrm{n}=48)$ & 13 & 35 \\
\hline Cerebellar $(\mathrm{n}=2)$ & 2 & - \\
\hline Cerebral parenchymal $(n=40)$ & 26 & 14 \\
\hline Total $(n=90)$ & 41 & 49 \\
\hline
\end{tabular}

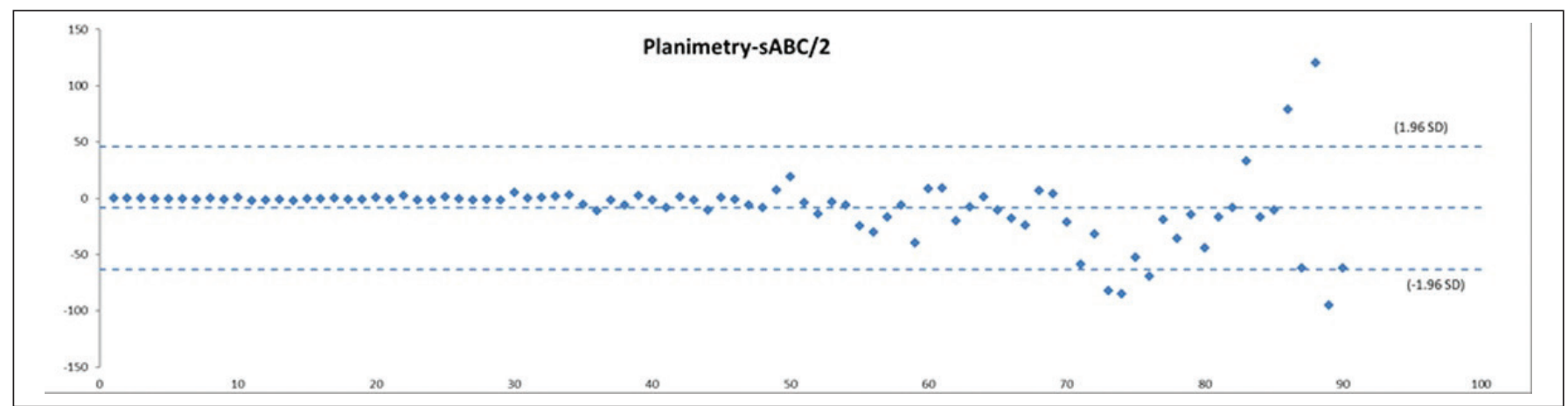

Figure 2: Arithmetic mean: Planimetry - sABC/2. 


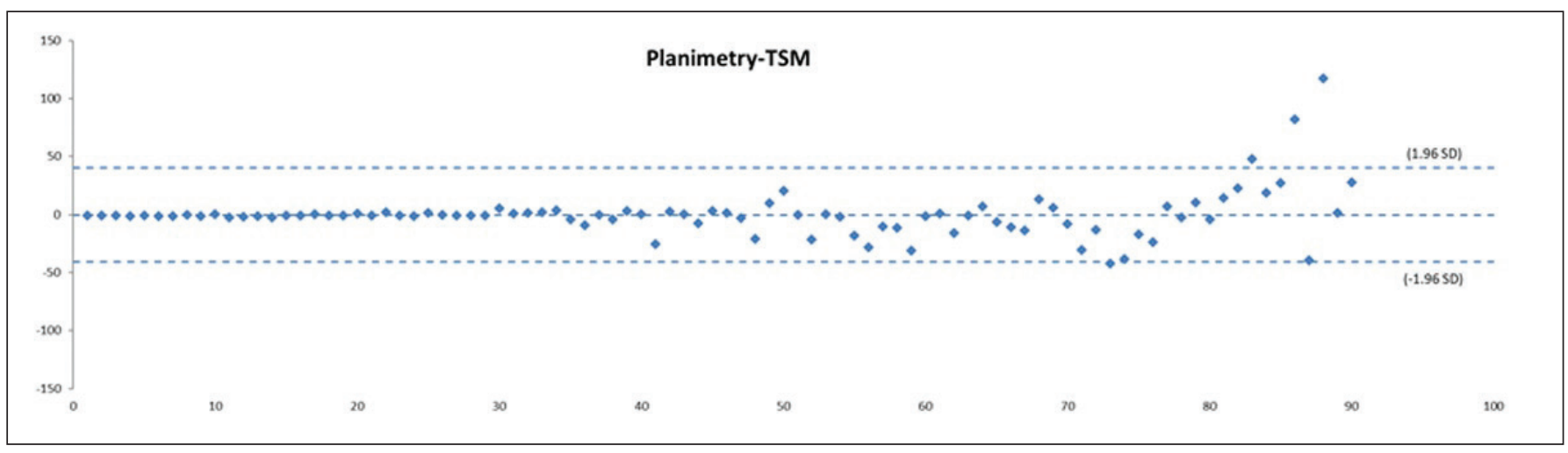

Figure 3: Arithmetic mean: Planimetry - TSM (Two step method).

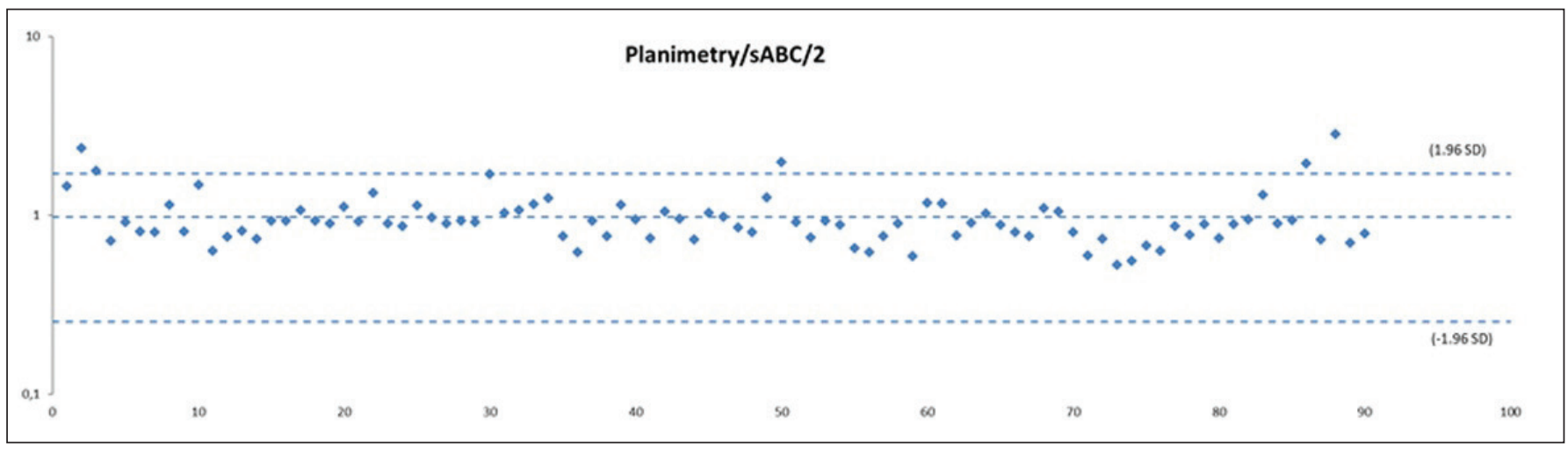

Figure 4: Geometric mean: Planimetry / sABC/2.

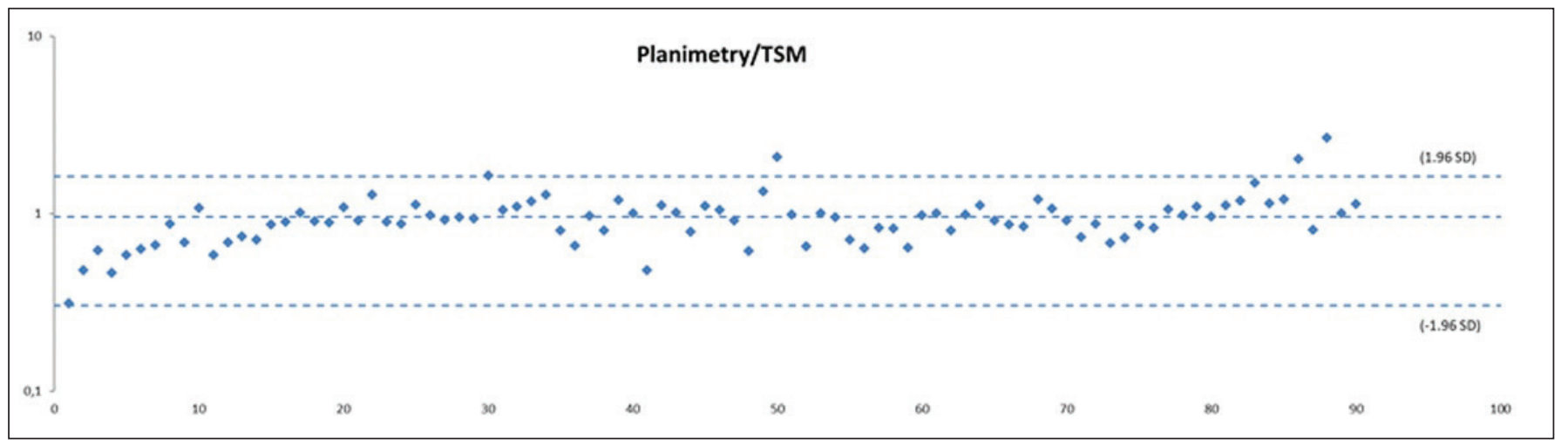

Figure 5: Geometric mean: Planimetry / TSM (Two step method).

Planimetry to $\mathrm{SABC} / 2$ and TSM ratios were all very close to 1 , which means that these methods only slightly overestimated and underestimated planimetry, respectively.

RMSE is another important metric for comparing methods. Table II and Table III demonstrate the RMSE values for hematomas less than $45 \mathrm{ml}$ and greater than $45 \mathrm{ml}$ respectively. For small $\mathrm{ICH}$ volumes, $0.45 \mathrm{ABC}+1$ and for large volumes $0.3 A B C+30$ perform better approximation than $\mathrm{SABC} / 2$ for all types of hematomas.

Volume errors of cerebral hematoma for all cases are shown in Figure 6.
Concordance between planimetry, sABC/2 and TSM were all high and obtained as 0.92 and 0.93 respectively as seen in Table IV.

Sensitivity and specificity values were obtained for differentiating a cerebral hematoma volume of $30 \mathrm{ml}$. When considering planimetry as the gold standard, $\mathrm{sABC} / 2$ had a sensitivity of $95.6 \%$ at a specificity of $95.4 \%$ and AUC: .99 , TSM had a sensitivity of $91.3 \%$ at a specificity of $95.4 \%$ and AUC: 0.99 . 


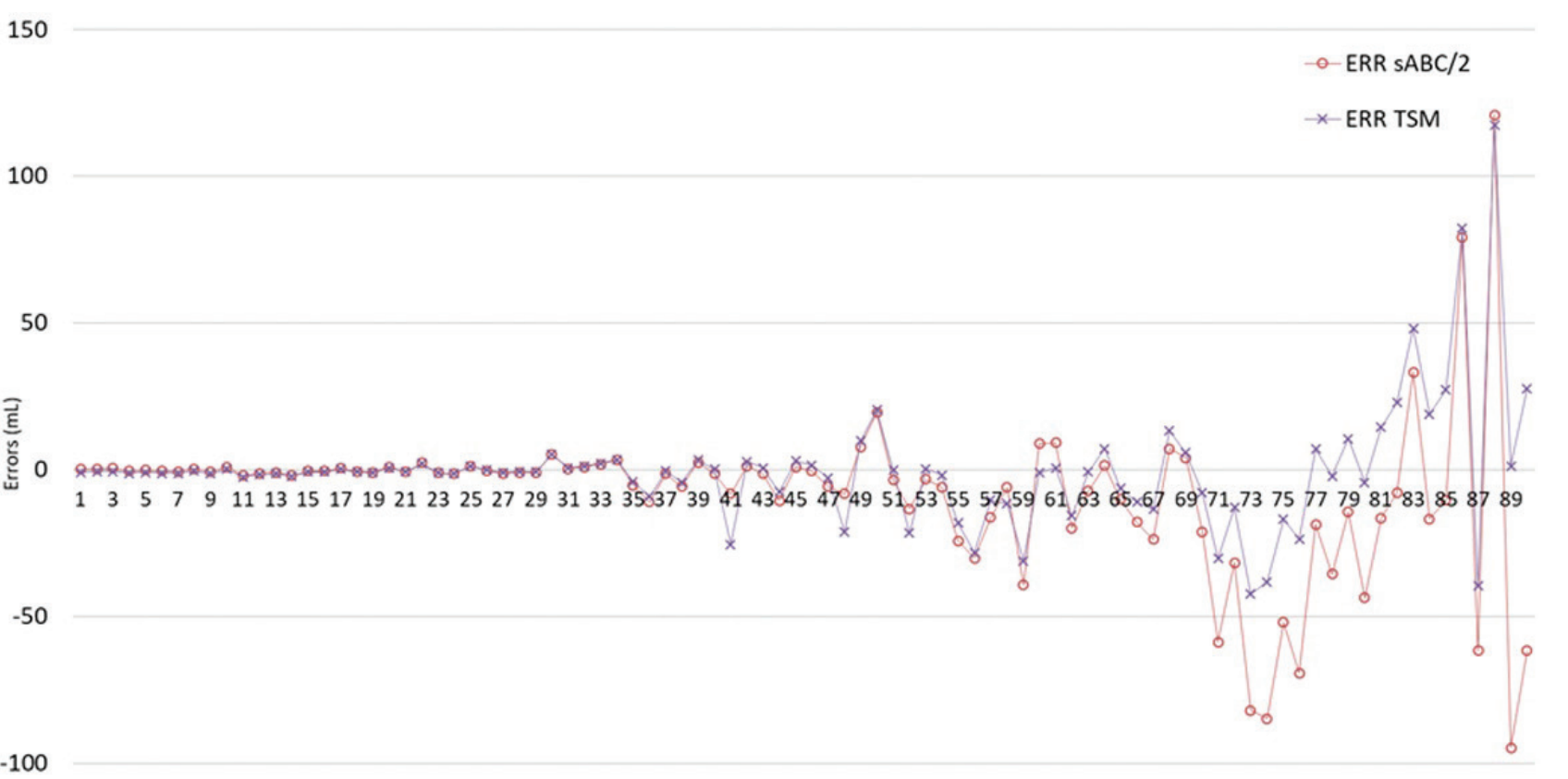

Figure 6: Errors of sABC/2 and two step method (TSM).

Table II: Root Mean Square Errors of ICH Volume for Less than $45 \mathrm{ml}$

\begin{tabular}{|c|c|c|c|}
\hline \multirow{2}{*}{${ }^{1} \mathrm{ICH}$ Type } & \multicolumn{3}{|c|}{ Formula and ${ }^{2}$ RMSE } \\
\hline & $\mathrm{ABC} / 2(\mathrm{ml})$ & $0.3 A B C+30(\mathrm{ml})$ & $0.45 A B C+1(\mathrm{ml})$ \\
\hline Subdural & 13.93 & 21.43 & 9.38 \\
\hline Irregular parenchymal & 8.53 & 25.46 & 8.07 \\
\hline Regular parenchymal & 3.94 & 26.02 & 3.85 \\
\hline
\end{tabular}

${ }^{1} \mathbf{I C H}$ (intracerebral hemorrhage), ${ }^{2} \mathbf{R M S E}$ ( Root mean square error).

Table III: Root Mean Square Errors of ICH Volume for Greater than $45 \mathrm{ml}$

\begin{tabular}{|c|c|c|c|}
\hline \multirow{2}{*}{${ }^{1} \mathrm{ICH}$ Type } & \multicolumn{3}{|c|}{ Formula and ${ }^{2} \mathrm{RMSE}$} \\
\hline & $\mathrm{ABC} / 2(\mathrm{ml})$ & $0.3 \mathrm{ABC}+30(\mathrm{ml})$ & $0.45 \mathrm{ABC}+1(\mathrm{ml})$ \\
\hline Subdural & 43.74 & 27.88 & 34.95 \\
\hline Irregular parenchymal & 73.05 & 62.27 & 70.22 \\
\hline Regular parenchymal & 27.46 & 16.09 & 17.74 \\
\hline
\end{tabular}

${ }^{1}$ ICH (intracerebral hemorrhage), ${ }^{2}$ RMSE (Root mean square error).

Table IV: ICH Concordance for sABC/2 and TMS as Compared to Planimetry

\begin{tabular}{lll}
\hline Method & ${ }^{1} \mathrm{ICH}$ & $95 \%{ }^{2} \mathbf{C l}$ \\
\hline SABC/2 & 0.92 & $(.88-.95)$ \\
\hline${ }^{3} \mathrm{TSM}$ & 0.93 & $(.89-.95)$ \\
\hline
\end{tabular}

${ }^{1} \mathbf{I C H}$ (intracerebral hemorrhage), ${ }^{2} \mathbf{C l}$ (Confidential Interval), ${ }^{3} \mathrm{TSM}$ (Two Step Method).

\section{DISCUSSION}

In the present study, the hematoma volumes calculated by $\mathrm{sABC} / 2$ and our new formula were found to be close to the values obtained by the planimetric method, and both the formulas were found to be highly correlated between different users.

Various grading scores have been used to predict the prognosis of spontaneous $\mathrm{PH}(5)$. The $\mathrm{ICH}$ score is most 
commonly used and can be easily calculated based on neurological examination and CT findings (5). The hematoma volume is one of the scoring criteria of $\mathrm{ICH}$ score and assessed as being lower or higher than $30 \mathrm{ml}$ (1). Khan et al. found that in patients with acute $\mathrm{PH}$, the sensitivity and specificity value of $\mathrm{sABC} / 2$ at distinguishing the volume over $30 \mathrm{ml}$ was $93.3 \%$ and $91.1 \%$, respectively (8). Likewise, as mentioned in the literature $(9,14)$, Hussein et al. found that the error rate of $\mathrm{sABC} / 2$ was $10 \%$ in haemorrhages $<20 \mathrm{~cm}^{3}$, whereas it was $37 \%$ in those $>40 \mathrm{~cm}^{3}(6)$. Wang et al. suggested the error rate of sABC/2 as $9.9 \%$ in a haemorrhage volume of $<20 \mathrm{ml}$, $16.7 \%$ in $20-40 \mathrm{ml}$ and $37.1 \%$ in $>40 \mathrm{ml}$ (14). This error rate, which increases parallel to the volume, generally tends to be overestimated. In the present study, sABC/2 overestimated planimetry, with mean differences of- $8.51 \mathrm{ml}$, whereas TSM method overestimated planimetry with only $-0.31 \mathrm{ml}$ of the mean difference. For differentiating a hematoma volume of $>30 \mathrm{ml}, \mathrm{sABC} / 2$ had a sensitivity of $95.6 \%$ at a specificity of $95.4 \%$ and AUC 0.99 , whereas TSM had a sensitivity of $91.3 \%$ at a specificity of $95.4 \%$ and AUC 0.99 , thus being close to each other. It should be noticed that the values of sensitivity and specificity are dependent on the number of cases that have approximately $30 \mathrm{ml}$ of volumes.

One of the difficulties in volume calculation is the shape of the hematoma. Irregular and discrete shapes were calculated using an ellipsoid volume formula. Xu et al. suggested that erroneous outcomes were more likely because of the hematoma shape compared to the hematoma volume (16). Erroneous results generally tend to be overestimated, and such erroneous results in hematoma with regular shape are by $3.33 \mathrm{~cm}^{3}(9.76 \%)$ and in irregular-shaped hematoma by $7.19 \mathrm{~cm}^{3}$ (18.37\%). Huttner et al. reported the over-measured volume by $\mathrm{sABC} / 2$ to be $32.1 \%$ in an irregular-shaped hematoma (7). Similar to the previous studies $(3,12)$, Khan et al. found that $\mathrm{SABC} / 2$ was much better than another formula, $\mathrm{C}$-weighted $\mathrm{ABC} / 2$, for measuring irregular-shaped hematoma (8). The planimetric correlation of our new formula and sABC/2 in irregular-shaped hematoma was $72.7 \%$.

For SHs, there is no scoring system to determine the treatment or prognosis. Although the indirect findings, such as midline shift, could have been used in surgical decision making, some of the studies have been done to calculate the volume of subdural hematomas in the literature. Gebel et al. reported that the correlation of $\mathrm{sABC} / 2$ with the planimetric method for acute $\mathrm{SH}$ volume was high (average volume, 91.0 $\mathrm{cm}^{3}$ and $82.4 \mathrm{~cm}^{3}$ with the $\mathrm{sABC} / 2$ and planimetric method, respectively), and it could be practically used at the bedside (4). In chronic SH, Sucu et al. found that the correlation of all the five different $S A B C / 2$ types, which they used at different measurement points, was high (13). For parenchymal cases, both the methods we used had approximately similar error values; however, the proposed method had a correlation of $91 \%$ with planimetric volume, which was slightly better than $\mathrm{sABC} / 2$ for subdural cases.

The initial diagnosis of $\mathrm{ICH}$ is generally made at the emergency room, and the emergency teams from different departments with different experiences work together. Therefore, the volume formula shall be easy to use. $A B C / 2$ is an ellipsoid volume formula and commonly used in radiology. Khan et al. reported a highdegree of coherence amongst the readers, comprising medical students, neurology residents and vascular neurologists (ICC: 0.96), with regard to sABC/2 (8). However, in a study about the reliability of $\mathrm{SABC} / 2$ amongst different readers, Hussein et al. found that the planimetric method correlation was lower for various readers with little experience at the incident scene in comparison to an experienced single reader (6). Divani et al. revealed that two radiologists performed volume calculations at an imaging laboratory, and found $\mathrm{SABC} / 2$ and planimetric method correlation to be high (0.91-1.0) amongst the readers, reasoning a high applicability rate of this formula (2). In the present study, a high degree of correlation between our method and $\mathrm{SABC} / 2$ was evident as well as between the two radiologists was observed (0.98). The present method is less practitioner-dependent. Furthermore, the degree of correlation between the planimetric method, proposed formula and $\mathrm{SABC} / 2$ were calculated and found to be equal.

The limitations of this study include a small sample size and thus our new formula needs to be tested with larger groups of patients. Furthermore, although the two formulas mentioned in the study may be easily applicable, they were used by two radiologists in the reporting room, rather than a practitioner or a clinician at the place of incident.

\section{CONCLUSION}

Our new formula has a high accuracy rate for both SHs and $\mathrm{PHs}$ and may prove to be simpler to use, fast and deliver the most accurate measurement, which would help the clinician in bedside management of the patients.

\section{口 REFERENCES}

1. Cuce F, Dandin O, Teomete U, Osman O, Ergin T, Tulum G, Aydin OU: Semi-automated calculation of intracranial haematoma volume with a new method. Injury 47(6):13611363, 2016

2. Divani AA, Majidi S, Luo X, Souslian FG, Zhang J, Abosch A, Tummala RP: The ABCs of accurate volumetric measurement of cerebral hematoma. Stroke 42:1569-1574, 2011

3. Freeman WD, Barrett KM, Bestic JM, Meschia JF, Broderick DF, Brott TG: Computer-assisted volumetric analysis compared with $\mathrm{ABC} / 2$ method for assessing warfarin-related intracranial hemorrhage volumes. Neurocrit Care 9:307-312, 2008

4. Gebel JM, Sila CA, Sloan MA, Granger CB, Weisenberger JP, Green CL, Topol EJ, Mahaffey KW: Comparison of the $\mathrm{ABC} / 2$ estimation technique to computer-assisted volumetric analysis of intraparenchymal and subdural hematomas complicating the GUSTO-1 trial. Stroke 29:1799-1801, 1998

5. Hemphill JC, Bonovich DC, Besmertis L, Manley GT, Johnston SC: The $\mathrm{ICH}$ score: A simple, reliable grading scale for intracerebral hemorrhage. Stroke 32:891-897, 2001 
6. Hussein HM, Tariq NA, Palesch YY, Qureshi Al; ATACH Investigators: ATACH investigators. Reliability of hematoma volume measurement at local sites in a multicenter acute intracerebral hemorrhage clinical trial. Stroke 44:237-239, 2013

7. Huttner HB, Steiner T, Hartmann M, Köhrmann M, Juettler E, Mueller S, Wikner J, Meyding-Lamade U, Schramm P, Schwab S, Schellinger PD: Comparison of $A B C / 2$ estimation technique to computer-assisted planimetric analysis in warfarin-related intracerebral parenchymal hemorrhage. Stroke 37:404-408, 2006

8. Khan M, Baird GL, Elias R, Rodriguez-Srednicki J, Yaghi S, Yan S, Collins S, Thompson BB, Wendell LC, Potter NS, Fehnel C, Saad A, Silver B: Comparison of intracerebral hemorrhage volume calculation methods and their impact on scoring tools. J Neuroimaging 27:144-148, 2017

9. Kothari RU, Brott T, Broderick JP, Barsan WG, Sauerbeck LR, Zuccarello M, Khoury J: The ABCs of measuring intracerebral hemorrhage volumes. Stroke 27:1304-1305, 1996

10. Maeda AK, Aguiar LR, Martins C, Bichinho GL, Gariba MA: Hematoma volumes of spontaneous intracerebral hemorrhage: The ellipse $(\mathrm{ABC} / 2)$ method yielded volumes smaller than those measured using the planimetric method. Arq Neuropsiquiatr 71:540-544, 2013

11. Morgan T, Zuccarello M, Narayan R, Keyl P, Lane K, Hanley $D$ : Preliminary findings of the minimally-invasive surgery plus rtPA for intracerebral hemorrhage evacuation (MISTIE) clinical trial. Acta Neurochir Suppl 105:147-151, 2008

12. Sheth KN, Cushing TA, Wendell L, Lev MH, Romero JM, Schwab K, Smith EE, Greenberg SM, Rosand J, Goldstein $\mathrm{JN}$ : Comparison of hematoma shape and volume estimates in warfarin versus non-warfarin related intracerebral hemorrhage. Neurocrit Care 12:30-34, 2010
13. Sucu HK, Gokmen M, Gelal F: The value of $X Y Z / 2$ technique compared with computer-assisted volumetric analysis to estimate the volume of chronic subdural hematoma. Stroke 36:998-1000, 2005

14. Wang CW, Juan CJ, Liu YJ, Hsu HH, Liu HS, Chen CY, Hsueh CJ, Lo CP, Kao HW, Huang GS: Volume dependent overestimation of spontaneous intracerebral hematoma volume by the ABC/2 formula. Acta Radiol 50:306-311, 2009

15. Webb AJS, Ullman NL, Morgan TC, Muschelli J, Kornbluth J, Awad IA, Mayo S, Rosenblum M, Ziai W, Zuccarrello M, Aldrich F, John S, Harnof S, Lopez G, Broaddus WC, Wijman C, Vespa P, Bullock R, Haines SJ, Cruz-Flores S, Tuhrim S, Hill MD, Narayan R, Hanley DF; MISTIE and CLEAR Investigators: MISTIE and CLEAR Investigators. Accuracy of the ABC/2 Score for intracerebral hemorrhage: Systematic review and analysis of MISTIE, CLEAR-IVH, and CLEAR III. Stroke 46:2470-2476, 2015

16. Xu X, Chen X, Zhang J, Zheng Y, Sun G, Yu X, Xu B: Comparison of the Tada formula with software slicer: Precise and low-cost method for volume assessment of intracerebral hematoma. Stroke 45:3433-3435, 2014

17. Yan P, Yan L, Hu T, Zhang Z, Feng J, Zhao H: Assessment of the accuracy of $A B C / 2$ variations in traumatic epidural hematoma volume estimation: A retrospective study. PeerJ 4:e1921, 2016

18. Zhao KJ, Zhang RY, Sun QF, Wang XQ, Gu XY, Qiang Q, Gao C, Shen JK: Comparisons of 2/3Sh estimation technique to computer-assisted planimetric analysis in epidural, subdural and intracerebral hematomas. Neurol Res 32(9):910-917, 2010 